\title{
Optimasi Pergerakan Motor Stepper 3 Axis dengan Metode Microstepping dan Pembuatan Unique Code pada Lead Frame
}

\author{
Alfino Suhendra, Nanta Fakih Prebianto, Nur Sakinah Asaad \\ Politeknik Negeri Batam, Jurusan Teknik Elektro, Batam \\ E-mail: alfinosuhendra1999@gmail.com
}

\begin{abstract}
Abstrak
Perkembangan teknologi industri saat ini memang tidak bisa diragukan lagi semenjak munculnya industri 4.0 yang sangat menunjang produktifitas dan efektifitas. Hal ini semakin menuntut setiap perusahaan untuk lebih berkembang dan dapat bersaing dalam dunia industry. Oleh karena itu, dibutuhkan sistem yang dapat mengurangi pemakaian tenaga manusia tetapi tetap meningkatkan jumlah produktifitas. Microstepping merupakan sebuah mekanisme pada industri yang menggunakan fungsi dasar pada motor stepper yaitu pergerakan, dengan mengurangi probabilitas yang mungkin dapat menyebabkan timbulnya permasalahan pada sistem itu sendiri. Sistem ini diterapkan pada alat yang sebelumnya sudah dibuat bernama "Chip RFID Tester" yang berfungsi untuk melakukan pergerakan dalam pembacaan chip RFID yang tertera pada lead frame. Untuk peningkatan efisiensi yang mampu dilakukan oleh Chip RFID Tester dengan menggunakan metode microstepping mencapai $\pm 50 \%$ dibandingkan dengan tidak menggunakan microstepping.
\end{abstract}

Kata kunci: Motor, Stepper, laser, Manufaktur, Optimasi

\section{Abstract}

The development of industrial technology today cannot be doubted since Industry 4.0 has greatly supported productivity and effectiveness. This increasingly requires every company to develop and be able to compete in the world industry. Therefore, we need a system that can reduce human labor but still increase the amount of productivity. Microstepping is a case in an industry that uses the basic function of a stepper motor, namely movement, with a probability that it might cause problems in the system itself. This system is applied to a device that has previously been made with the name "Chip RFID Tester" which functions to make movements in reading the RFID chip printed on the lead frame. For the increase in efficiency, the RFID Chip Tester by using the microstepping method reaches $\pm 50 \%$ compared to not using microstepping.

Keywords: Motor, Stepper, laser, Manufacturing, Optimization 


\section{Pendahuluan}

Industri merupakan dunia teknologi yang memiliki peningkatan mutu kerja yang sangat signifikan dari setiap tahunnya, hal ini dikarenakan sistem atau mesin di industri yang memiliki kecepatan dan tingkat produktifitas yang tinggi, dan dalam hal ini lebih difokuskan pada mesin uji coba chip RFID (Radio Frequency Identification) untuk bekerja cepat, tepat dan efisien.

Motor stepper 3 Axis digunakan dalam mesin yang difungsinya sebagai miniatur CNC (Computer Numerical Control) ataupun mesin yang bertujuan untuk membuat pergerakan berupa pola atau karakter. Motor stepper dipilih karena memiliki pergerakan yang dapat diatur koordinat maupun sudut putarnya sehingga dapat mencapai tingkat akurasi yang baik. Pada proyek ini penulis memilih metode pergerakan dengan menggunakan microstepping dikarenakan lebih efisien jika dibandingkan dengan metode yang lain seperti metode full step dan half step.

Half-stepping dan microstepping menyebabkan motor stepper akan berputar dengan cara yang lebih halus sehingga suara putaran rotor menjadi lebih tidak terdengar. Jumlah step bisa naik secara signifikan,bahkan bisa mencapai 256 kali lipat. Jadi, untuk sebuah motor stepper dengan step angle $\theta$ sebesar $1.8^{\circ}$ akan memberikan $256 \times 200=51200$ step untuk setiap satu putarannya. Akan tetapi, presisi untuk microstepping lebih buruk dibandingkan presisi untuk full-stepping [2].

Adapula fungsi lain yang diterapkan pada proyek akhir ini adalah design marking yang memerlukan sistem pergerakan untuk membentuk suatu karakter pada lead frame untuk dijadikan sebagai unique code pada setiap produk yang telah diuji dan dilaporkan bahwa telah lulus uji coba.

Dalam pengerjaan proyek ini penulis mengimplementasikan media kendali yaitu Raspberry $\mathrm{Pi}$, hal ini dikarenakan Raspberry $\mathrm{Pi}$ merupakan mini $P C$ yang dijalankan dengan menggunakan layar monitor sebagai tampilan layarnya, hal ini memudahkan dalam membuat GUI (Graphic User Interface) sebagai tampilan monitoring. Dan jika menggunakan Raspberry $\mathrm{Pi}$ ini juga mempermudah dalam pengiriman ke database, karena Raspberry $\mathrm{Pi}$ sendiri sangat mudah diakses dalam hubungan komunikasi ke jaringan internet.

Adapula perbandingan yang dilakukan oleh penulis untuk menguji kemampuan dari alat Chip RFID Tester ini dengan RF LF \& HF Performance Tester T8200PRO-G sebagai acuan dalam melihat performa dari alat tersebut.

Maka dari itu penulis bertujuan untuk menganalisa optimasipergerakan motor stepper 3 Axis dengan metode microstepping dan pembuatan unique code Pada Lead Frame berbasis Raspberry Pi.

\section{Metode Penelitian}

\section{A. Perancangan Metode}

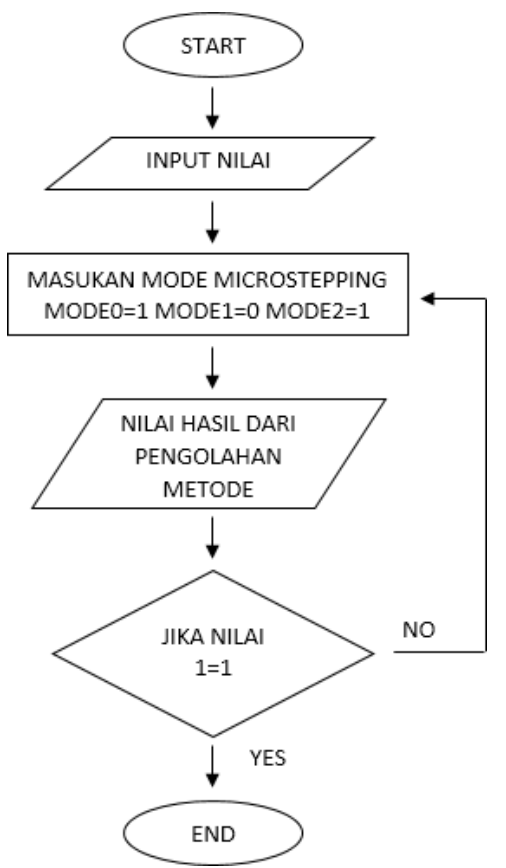

Gambar 1. Diagram alir Perancangan metode

Pada gambar 1 merupakan cara kerja dari uji coba metode microstepping sendiri dengan memasukan nilai pada tiga pin mode sebagai perbandingan nilai untuk mendapatkan step yang diinginkan, dan perbandingan jika nilai 1 mendapatkan hasil output sama, maka sistem akan selesai yang berarti implementasi metode microstepping berhasil. 

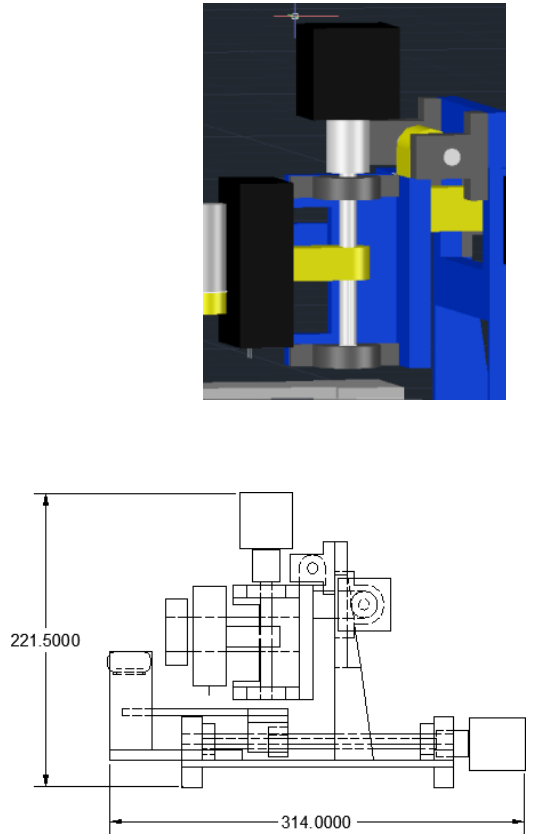

Tampak Depan

Tampak

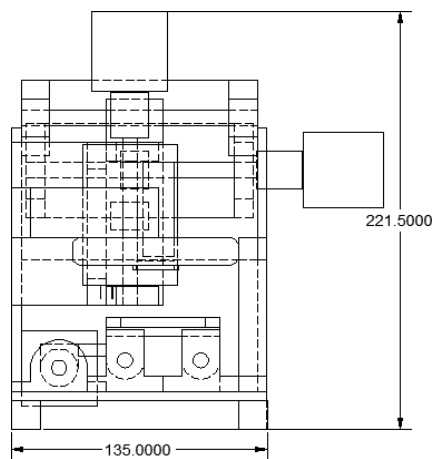

Gambar 2. Rancangan design akhir

Pada perancangan mekanik ini telah didesain dengan ukuran alat yang seusai dengan aslinya dan beberapa komponen yang itambahkan pada alat ini seperti laser yang akan dijadikan sebagai media tulis dalam pembuatan unique code.

\section{B. Pengujian}

Sub bab ini merupakan bukti pengujian dari pelaksanaan dan penerapan metode yang sesuai dengan judul atau tujuan untuk penerapan metode microstepping, pengujian ini dibagi dalam 2 point yaitu pengujian metode microstepping dan pengujian laser.

\section{Pengujian Metode Microstepping}

Pengujian ini dilakukan dengan menggunakan program yang dijalankan pada Raspberry $\mathrm{Pi}$ dengan menggunakan bahasa pemograman Python dan membutuhkan driver sebagai kendali tegangan maupun arus pada motor stepper, yang dimana berfungsi untuk mengatur polaritas pada motor sesuai dengan input yang diberikan sesuai dengan program yang telah dibuat.

Adapula cara untuk mengaktifkan metode microstepping ini dengan program sebagai berikut:

Tabel 1. Metode Setup

\begin{tabular}{|l|l|l|l|}
\hline Mode1 & Mode2 & Mode3 & Metode \\
\hline 0 & 0 & 0 & Full \\
\hline 0 & 0 & 1 & Half \\
\hline 0 & 1 & 0 & $1 / 4$ \\
\hline 0 & 1 & 1 & $1 / 8$ \\
\hline 1 & 0 & 0 & $1 / 16$ \\
\hline 1 & 0 & 1 & $1 / 32$ \\
\hline
\end{tabular}

Dengan memasukan nilai mode seperti pada tabel 1 pada pin microcontroller, akan memberikan perintah pada driver untuk mengaktifkan salah satu dari mode yang tersedia.

Hasil yang didapatkan dari penerapan metode microstepping ini dibuktikan dengan memasukan nilai 200 step sesuai dengan karakteristik dari motor yang memiliki langkah putar 200 kali atau 200 titik dan dengan menggunakan metode microstepping ini hasil yang didapatkan sebagai berikut:

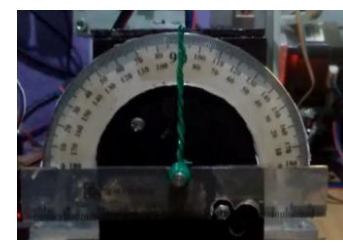

Gambar 3. Titik 0

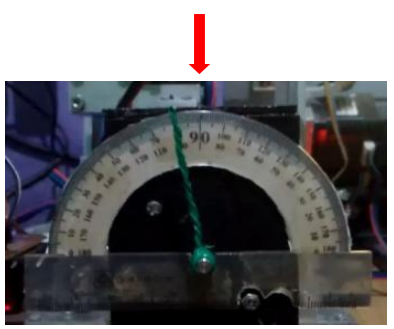

Gambar 4. 200 Step Microstepping 


\section{Pengujian Laser}

Pengujian pada laser dilakukan dengan cara mengatur tingkat fokus pada laser dengan memutar bagian lensa sesuai dengan jarak yang diinginkan, hal ini akan mempengaruhi intensitas cahaya yang ditimbulkan oleh laser karena membuat sudut pandang laser seniri menjadi lebih kecil dan mendapatkan titik lebur yang tepat sesuai dengan sudut yang diatur.

\section{Perbandingan kecepatan Reading Test}

Pada pembuatan alat ini tentunya dibutuhkan pengujian untuk menentukan nilai chip yang berfungsi dengan baik ataupun tidak, hal ini juga membutuhkan waktu atau proses pada controller untuk mengidentifikasi pada nilai chip yang terbaca agar dapat diketahui hasilnya.

Berikut telah penulis coba membandingkan nilai kecepatan proses baca pada Chip RFID Tester dengan RF LF \& HF Performance Tester T8200PRO-G yang hasilnya sebagai berikut:

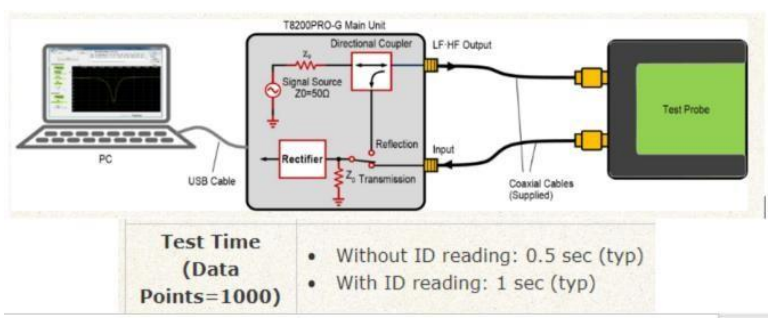

Gambar 5. reading test $R F L F \&$ HF Performance TesterT8200PRO-G [6].

Tabel 2. Perbandingan Kecepatan Baca Chip

\begin{tabular}{|l|l|c|}
\hline No & Device & $\begin{array}{c}\text { Kecepetan } \\
\text { baca(detik) }\end{array}$ \\
\hline 1 & Chip RFID Tester & 0.1 \\
\hline 2 & $\begin{array}{l}\text { RF LF \& HF Performance } \\
\text { Tester T8200PRO-G }\end{array}$ & 1 \\
\hline
\end{tabular}

Perbedaan yang cukup signifikan antara Chip RFID Tester dengan RF LF \& HF Performance Tester T8200PRO-G karena dapat membaca 10 kali lipat lebih cepat, untuk Chip RFID Tester sendiri dibuktikan dapat membaca dengan kecepatan 0.1 detik atau $100 \mathrm{~ms}$ adalah pada saat program dijalankan, maka sistem kendali mesin memberikan waktu 100 ms untuk membaca chip dan melanjutkan pergerakan motor setelah waktu yang diberikan oleh sistem untuk membaca chip telah habis, oleh karena itu kecepatan baca yang mampu dicapai oleh mesin Chip RFID Tester \pm 100 ms.

\section{Hasil dan Diskusi}

Pada bab ini akan menjelaskan dan membuktikan hasil dari implementasi metode ini, yang dimana mencakup nilai time /div dari metode microstepping dan data dari pengaturan jarak fokus pada laser maupun pembuatan karakter yang akan dijelaskan secara terperinci pada bab ini.

\section{A. Data Pengukuran Sinyal \\ Microstepping}

Pengukuran sinyal microstepping dapat dilakukan dengan menggunakan osiloskop yang menampilkan gelombang kotak seperti pada gambar 11, singkatnya yang dilihat pada pengukuran sinyal ini adalah jarak wktu dari setiap peak to peak yang memberikan informasi untuk perpindahan pada setiap stepnya, yang dimana jika nilai pengali waktu semakin kecil maka step yang digunakan akan semakin besar.

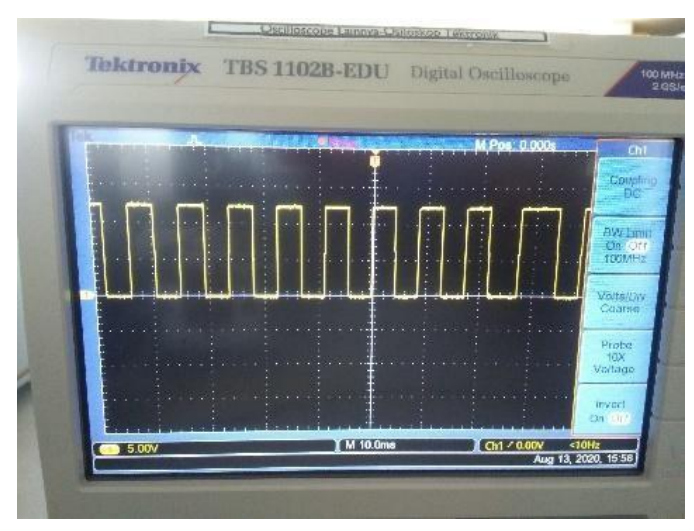

Gambar 6. Pengukuran sinyal full step

Pada gambar 6 adalah bentuk dari sinyal motor dalam mode full step yang dimana pengali waktunya lebih besardibandingkan dengan mode microstepping, perbedaan yang terdapat pada mode ini adalah jumlah step pada 1 putaran akan normal atau sesaui spesifikasi dari motor yang digunakan, secara singkat mode ini adalah mode real atau yang sebenarnya. 


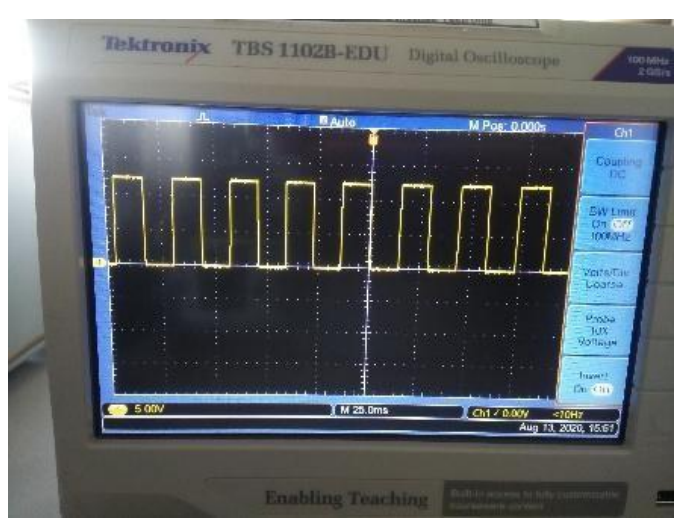

Gambar 7. Pengukuran Sinyal Microstepping

Dibandingkan dengan mode yang sebelumnya, mode yang seperti pada gambar 7 memiliki ketelitian yang lebih tinggikarena dapat melakukan step yang lebih banyak yaitu 32 kali lipat dari step real. Untuk waktu pengali yang digunakan juga lebih besar yaitu $25 \mathrm{~ms}$, berbeda dengan mode full step sebelumnya yang menggunakan waktu pengali $10 \mathrm{~ms}$.

Pada kesimpulannya nilai yang terdapat pada gambar 7 adalah nilai dari perubahan waktu pada setiap mode, dan nilai ini juga mempengaruhi kecepatan pada setiap mode karena jika nilai yang diberikan pada setiap mode adalah sama maka tentunya kecepatan yang tercepat dihasilkan oleh mode Full karena step nya lebih sedikit dibandingan dengan mode yang lain.

\section{B. Data Perbandingan jarak dan Sudut Pada Laser}

Pada data ini akan lebih dirujukan dalam pengaturan titik fokus laser pada jarak tertentu, untuk nilai data yang diambil sejumlah 150 data dengan jarak yang konstan naik agar didapatkannya titik yang pas antara jarak dan pengaturan fokus laser yang diambil dalam satuan jarak.

Berikut nilai dari jarak yang dikonversikan dalam bentuk grafik sesuai pada gambar 13 yang dapat dilihat untuk pengambilan 150 data dengan selisih 10 derajat pada setiap perubahan.

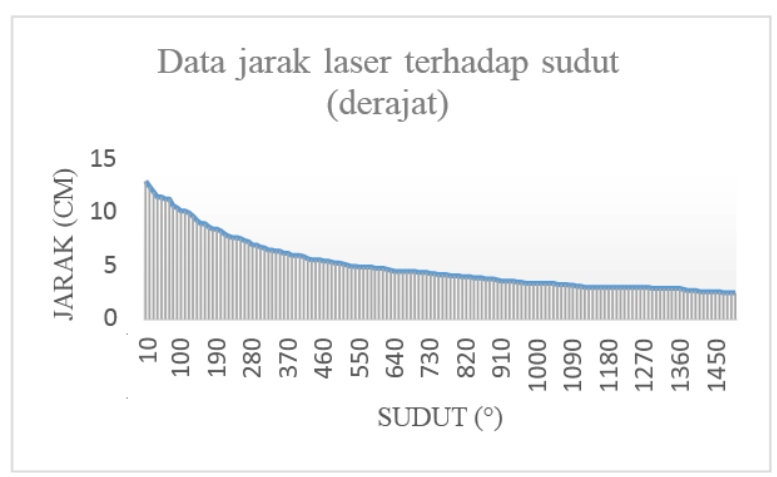

Gambar 8. perbandingan nilai jarak terhadap sudut

Untuk gambar 8 adalah hasil grafik dari perbandingan nilai jarak terhadap sudut, pada grafik dapat dilihat nilai konstan untuk derajat yang karena nilai dijadikan sebagai patokan untuk mendapatkan nilai jarak yang dibutuhkan.

Dapat disimpulkan bahwa pengaturan fokus pada laser cukup mudah untuk diatur dan didapatkan, bila mengacu pada grafik diatas maka akurasi yang didapatkan cukup bagus untuk nilai perbandingan jarak dan sudut karena memiliki bentuk grafik dengan error yang sedikit.

\section{Data Waktu Pada Proses Chip RFID Tester}

Untuk mengetahui hasil dari kecepatan yang dapat diselesaikan oleh alat ini, penulis sudah membuat program counting atau split time untuk mengkonfirmasi waktu pada setiap perpindahan chip dengan toleransi waktu pada setiap perpindahan \pm 0.1 detik.

Tabel 3. Perpindahan waktu uji coba pada setiap chip

\begin{tabular}{|c|c|c|c|c|c|c|c|}
\hline \multirow{2}{*}{ No } & \multirow{2}{*}{ Posisi } & \multicolumn{5}{|c|}{ Waktu (detik) } \\
\cline { 3 - 8 } & & $\mathbf{1}$ & $\mathbf{2}$ & $\mathbf{3}$ & $\mathbf{4}$ & $\mathbf{5}$ & $\begin{array}{r}\text { Rata- } \\
\text { rata }\end{array}$ \\
\hline 1 & inisial - c1 & 14.57 & 14.55 & 14.62 & 14.64 & 14.76 & 14.628 \\
\hline 2 & $\mathrm{c} 1-\mathrm{c} 2$ & 2.2 & 2.24 & 2.22 & 2.23 & 2.22 & 2.222 \\
\hline 3 & $\mathrm{c} 2-\mathrm{c} 3$ & 2.21 & 2.21 & 2.21 & 2.2 & 2.2 & 2.206 \\
\hline 4 & $\mathrm{c} 3-\mathrm{c} 4$ & 1.38 & 1.36 & 1.37 & 1.39 & 1.35 & 1.37 \\
\hline 5 & $\mathrm{c} 4-\mathrm{c} 5$ & 2.22 & 2.2 & 2.25 & 2.23 & 2.22 & 2.224 \\
\hline 6 & $\mathrm{c} 5-\mathrm{c} 6$ & 2.22 & 2.2 & 2.2 & 2.21 & 2.22 & 2.21 \\
\hline 7 & $\mathrm{c} 6-\mathrm{c} 7$ & 1.35 & 1.35 & 1.36 & 1.36 & 1.38 & 1.36 \\
\hline 8 & $\mathrm{c} 7-\mathrm{c} 8$ & 2.25 & 2.24 & 2.22 & 2.23 & 2.21 & 2.23 \\
\hline 9 & $\mathrm{c} 8-\mathrm{c} 9$ & 2.2 & 2.2 & 2.21 & 2.2 & 2.24 & 2.21 \\
\hline 10 & $\mathrm{c} 9-\mathrm{c} 10$ & 1.37 & 1.33 & 1.37 & 1.36 & 1.36 & 1.358 \\
\hline 11 & $\mathrm{c} 10-\mathrm{c} 11$ & 2.22 & 2.29 & 2.2 & 2.24 & 2.2 & 2.23 \\
\hline 12 & $\mathrm{c} 11-\mathrm{c} 12$ & 2.22 & 2.23 & 2.21 & 2.22 & 2.2 & 2.216 \\
\hline 13 & $\mathrm{c} 12-\mathrm{c} 13$ & 1.37 & 1.36 & 1.35 & 1.37 & 1.35 & 1.36 \\
\hline 14 & $\mathrm{c} 13-\mathrm{c} 14$ & 2.22 & 2.21 & 2.23 & 2.21 & 2.21 & 2.216 \\
\hline 15 & $\mathrm{c} 14-\mathrm{c} 15$ & 2.23 & 2.2 & 2.21 & 2.22 & 2.21 & 2.214 \\
\hline 16 & $\mathrm{c} 15-\mathrm{c} 16$ & 1.37 & 1.37 & 1.38 & 1.35 & 1.42 & 1.378 \\
\hline 17 & $\mathrm{c} 16-\mathrm{c} 17$ & 2.22 & 2.21 & 2.24 & 2.21 & 2.25 & 2.226 \\
\hline 18 & $\mathrm{c} 17-\mathrm{c} 18$ & 2.2 & 2.22 & 2.21 & 2.22 & 2.47 & 2.264 \\
\hline 19 & $\mathrm{c} 18-\mathrm{c} 19$ & 1.36 & 1.36 & 1.36 & 1.37 & 1.46 & 1.382 \\
\hline & & & & & & & \\
\hline
\end{tabular}




\begin{tabular}{|l|l|l|c|c|c|c|c|}
\hline 20 & $\mathrm{c} 19-\mathrm{c} 20$ & 2.24 & 2.22 & 2.23 & 2.21 & 2.2 & 2.22 \\
\hline 21 & $\mathrm{c} 20-\mathrm{c} 21$ & 2.21 & 2.2 & 2.2 & 2.19 & 2.26 & 2.212 \\
\hline 22 & $\mathrm{c} 21-\mathrm{c} 22$ & 1.37 & 1.35 & 1.36 & 1.34 & 1.41 & 1.366 \\
\hline 23 & $\mathrm{c} 22-\mathrm{c} 23$ & 2.14 & 2.2 & 2.23 & 2.29 & 2.14 & 2.2 \\
\hline 24 & $\mathrm{c} 23-\mathrm{c} 24$ & 2.22 & 2.2 & 2.21 & 2.19 & 2.18 & 2.2 \\
\hline 25 & $\mathrm{c} 24-\mathrm{c} 25$ & 1.35 & 1.35 & 1.35 & 1.4 & 1.36 & 1.362 \\
\hline 26 & $\mathrm{c} 25-\mathrm{c} 26$ & 2.23 & 2.21 & 2.21 & 2.18 & 2.24 & 2.214 \\
\hline 27 & $\mathrm{c} 26-\mathrm{c} 27$ & 2.13 & 2.2 & 2.22 & 2.24 & 2.18 & 2.194 \\
\hline 28 & $\mathrm{c} 27-\mathrm{c} 28$ & 1.34 & 1.35 & 1.38 & 1.36 & 1.35 & 1.356 \\
\hline 29 & $\mathrm{c} 28-\mathrm{c} 29$ & 2.24 & 2.21 & 2.19 & 2.25 & 2.26 & 2.23 \\
\hline 30 & $\mathrm{c} 29-\mathrm{c} 30$ & 2.21 & 2.21 & 2.2 & 2.21 & 2.16 & 2.198 \\
\hline 31 & $\mathrm{c} 30-\mathrm{c} 31$ & 1.37 & 1.35 & 1.35 & 1.35 & 1.33 & 1.35 \\
\hline 32 & $\mathrm{c} 31-\mathrm{c} 32$ & 2.23 & 2.2 & 2.2 & 2.22 & 2.29 & 2.228 \\
\hline 33 & $\mathrm{c} 32-\mathrm{c} 33$ & 2.24 & 2.21 & 2.21 & 2.25 & 2.18 & 2.218 \\
\hline 34 & $\mathrm{c} 33-\mathrm{c} 34$ & 1.38 & 1.36 & 1.36 & 1.36 & 1.37 & 1.366 \\
\hline 35 & $\mathrm{c} 34-\mathrm{c} 35$ & 2.22 & 2.2 & 2.18 & 2.23 & 2.23 & 2.212 \\
\hline 36 & $\mathrm{c} 35-\mathrm{c} 36$ & 2.21 & 2.2 & 2.22 & 2.23 & 2.27 & 2.226 \\
\hline 37 & $\mathrm{c} 36-$ inisial & 3.99 & 3.99 & 4.01 & 3.95 & 4.05 & 3.998 \\
\hline & & & & & & & \\
& & & & & & & \\
\hline
\end{tabular}

Dari tabel 3 diatas dapat dilihat bahwa hasil dari perpindahan pembacaan setiap chip tidak terlalu signifikan perbedaannya dikarenakan waktu yang ditetapkan pada proses pergerakan memiliki nilai yang sama. Dengan dilakukannya pengambilan data sebanyak 5 kali berfungsi untuk mendapatkan nilai rata-rata untuk dijadikan sebagai acuan perbandingan dengan hasil operasi pengerjaan mesin sebelumnya seperti pada tabel 4.

Jika dibandingkan dengan kecepatan dari hasil pengerjaan yang sebelumnya adalah sebagai berikut:

Tabel 4. Perbandingan waktu operasi sistem microstepping dengan sebelumnya

\begin{tabular}{|c|c|c|c|}
\hline No & Posisi & Sebelum & Sesudah \\
\hline 1 & inisial - c1 & 6.99 & 14.628 \\
\hline 2 & $\mathrm{c} 1-\mathrm{c} 2$ & 2.03 & 2.222 \\
\hline 3 & $\mathrm{c} 2-\mathrm{c} 3$ & 2.09 & 2.206 \\
\hline 4 & $\mathrm{c} 3-\mathrm{c} 4$ & 6.13 & 1.37 \\
\hline 5 & $\mathrm{c} 4-\mathrm{c} 5$ & 2.05 & 2.224 \\
\hline 6 & $\mathrm{c} 5-\mathrm{c} 6$ & 2.05 & 2.21 \\
\hline 7 & $\mathrm{c} 6-\mathrm{c} 7$ & 6.47 & 1.36 \\
\hline 8 & $\mathrm{c} 7-\mathrm{c} 8$ & 2.04 & 2.23 \\
\hline 9 & $\mathrm{c} 8-\mathrm{c} 9$ & 2.05 & 2.21 \\
\hline 10 & $\mathrm{c} 9-\mathrm{c} 10$ & 6.13 & 1.358 \\
\hline 11 & $\mathrm{c} 10-\mathrm{c} 11$ & 2.03 & 2.23 \\
\hline 12 & $\mathrm{c} 11-\mathrm{c} 12$ & 2.04 & 2.216 \\
\hline 13 & $\mathrm{c} 12-\mathrm{c} 13$ & 6.22 & 1.36 \\
\hline 14 & $\mathrm{c} 13-\mathrm{c} 14$ & 2.04 & 2.216 \\
\hline 15 & $\mathrm{c} 14-\mathrm{c} 15$ & 2.06 & 2.214 \\
\hline 16 & $\mathrm{c} 15-\mathrm{c} 16$ & 6.17 & 1.378 \\
\hline 17 & $\mathrm{c} 16-\mathrm{c} 17$ & 2.04 & 2.226 \\
\hline 18 & $\mathrm{c} 17-\mathrm{c} 18$ & 2.03 & 2.264 \\
\hline 19 & $\mathrm{c} 18-\mathrm{c} 19$ & 6.31 & 1.382 \\
\hline
\end{tabular}

\begin{tabular}{|c|c|c|c|}
\hline 20 & c19- c20 & 2 & 2.22 \\
\hline 21 & c20 - c21 & 2.04 & 2.212 \\
\hline 22 & $c 21-c 22$ & 6.15 & 1.366 \\
\hline 23 & $c 22-c 23$ & 2.04 & 2.2 \\
\hline 24 & c23 - c24 & 2 & 2.2 \\
\hline 25 & c24 - c25 & 6.17 & 1.362 \\
\hline 26 & $c 25-c 26$ & 2.04 & 2.214 \\
\hline 27 & $c 26-c 27$ & 2.07 & 2.194 \\
\hline 28 & $c 27-c 28$ & 6.21 & 1.356 \\
\hline 29 & $c 28-c 29$ & 2.05 & 2.23 \\
\hline 30 & c29- c30 & 2.06 & 2.198 \\
\hline 31 & c30-c31 & 6.42 & 1.35 \\
\hline 32 & $c 31-c 32$ & 2.09 & 2.228 \\
\hline 33 & c32-c33 & 2.06 & 2.218 \\
\hline 34 & c33-c34 & 6.28 & 1.366 \\
\hline 35 & c34-c35 & 2.21 & 2.212 \\
\hline 36 & c35-c36 & 2.09 & 2.226 \\
\hline 37 & c36 - inisial & 4.96 & 3.998 \\
\hline & Total & 129.91 & 86.854 \\
\hline
\end{tabular}

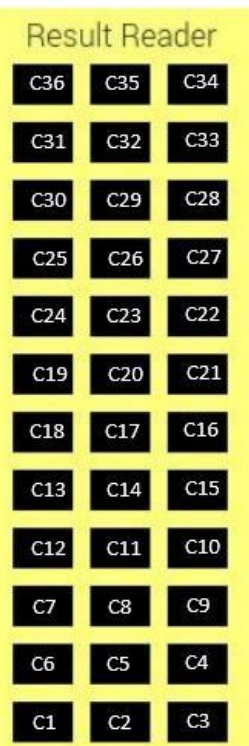

Gambar 9. Posisi Peletakan Chip

Sehingga dapat disimpulkan waktu yang dihasilkan dari projek sebelumnya dengan yang setalah diperbarui dengan microstepping lebih cepat dan efisien sebesar $\pm 50 \%$. Hal ini dikarenakan kecepatan waktu yang dicapai dari alat ini dapat dipercepat hamper setengah dari waktu sebelum metode microstepping ini diterapkan.

$\mathrm{Hal}$ ini dikarenakan metode microstepping dapat membuat pergerakan motor menjadi lebih halus sehingga mengurangi noise pada motor, dan untuk pergerakannya juga lebih singkat dibandingkan dengan sebelumnya 


\section{Data Waktu Pada Penulisan Karakter}

Dalam setiap penulisan karakter menggunakan media laser, maka dibutuhkan waktu yang berbeda karena jumlah gerakan yang dihasilkan pun juga bervariasi. Berikut nilai dari pembuatan setiap karakter dengan menggunakan media laser, dan nilai waktu diambil dengan menggunakan program yang sama saat melakukan uji coba chip yaitu dengan program counting atau split time, dengan toleransi waktu pada setiap pembuatan karakternya \pm 0.1 detik.

Tabel 5. Waktu pembuatan karakter

\begin{tabular}{|c|c|c|c|c|c|}
\hline No & Karakter & $\begin{array}{c}\text { Waktu } \\
\text { (detik) }\end{array}$ & No & Karakter & $\begin{array}{c}\text { Waktu } \\
\text { (detik) }\end{array}$ \\
\hline 1 & $\begin{array}{c}\text { Mulai } \\
\text { inisial }\end{array}$ & 9.59 & 14 & $\mathrm{c}$ & 9.05 \\
\hline 2 & 0 & 9.08 & 15 & $\mathrm{~d}$ & 11.52 \\
\hline 3 & 1 & 6.31 & 16 & $\mathrm{e}$ & 9.03 \\
\hline 4 & 2 & 9.04 & 17 & $\mathrm{f}$ & 7.81 \\
\hline 5 & 3 & 11.79 & 18 & $\mathrm{~h}$ & 8.81 \\
\hline 6 & 4 & 8.80 & 19 & $\mathrm{j}$ & 10.29 \\
\hline 7 & 5 & 11.72 & 20 & $\mathrm{l}$ & 6.32 \\
\hline 8 & 6 & 14.25 & 21 & $\mathrm{n}$ & 6.34 \\
\hline 9 & 7 & 6.32 & 22 & $\mathrm{p}$ & 9.04 \\
\hline 10 & 8 & 11.49 & 23 & $\mathrm{t}$ & 9.08 \\
\hline 11 & 9 & 11.51 & 24 & $\mathrm{u}$ & 11.27 \\
\hline 12 & $\mathrm{a}$ & 11.49 & 25 & $\mathrm{y}$ & 11.49 \\
\hline 13 & $\mathrm{~b}$ & 11.49 & 26 & $\begin{array}{c}\text { Kembali } \\
\text { inisial }\end{array}$ & 7.78 \\
\hline
\end{tabular}

\section{Simpulan}

Waktu Pengerjaan yang singkat dapat dicapai dengan menggunakan metode microstepping dan telah terbukti $\pm 50 \%$ lebih efisien dan lebih baik dalam pengawatan untuk motor stepper sendiri. Penerapan metode microstepping telah diterapkan dan menghasilkan pergerakan yang lebih akurat sesuai dengan data yang akurat dan valid.

Perlunya dilakukan perbaikan dan peningkatan pada bagian mekanik, karena bentuk yang terlalu padat sehingga membuat ruang bebasnya sedikit sehingga pada saat melakukan maintenance kurang efektif. Pergerakan yang dilakukan masih terbatas dengan gerakan vertical dan horizontal sehingga belum bisa melakukan gerakan linear dengan 2 motor.

\section{Daftar Pustaka}

[1] Arief Wisnu Wardhana dan Daru Tri Nugroho, "Pengontrolan Motor Stepper Menggunakan Driver DRV 8825 Berbasis Signal Square Wave dari Timer Mikrokontroller AVR", Jurnal Nasional Teknik Elektro, Vol. 7, No. 1, Maret 2018.

[2] Marc McComb, "Introduction to Stepper Motors Part 2: Stepper Motor Control”, Microchip, 2007

[3] Texas Instrument, "DRV8825 Stepper Motor Controller", 2014

[4] Indra A Eko Prasetyo dan Rikie Kartadie, "Sistem Keamanan Area Parkir Stkip Pgri Tulungagung Berbasis Radio Frequency Identification (Rfid)", JOEICT (Jurnal of Education and Information Communication Technology), Volume 3, Nomor 1, Maret 2019.

[5] Marti Deans. "CNC Coordinate System Made Easy" Internet: https://www.autodesk.com/products/fusion360/blog/cnc-coordinate system-made-easy/, 2018.

[6] rsid-solutions. "RF LF \& HF Performance Tester T8200PRO-G" Internet: http://www.rsid-

solu-

tions.com/products/RFID Inlay Tag/318.html ?gclid=EAlalQobChMlovTntYLS7gIVCMWWC h2veQYWEAAYASAAEgIPPPD BwE 